\title{
Erratum to: Appraisal of testicular volumes: volumes matching ultrasound values referenced to stages of genital development
}

\author{
Juan F. Sotos ${ }^{1 *}$ and Naomi J. Tokar ${ }^{2}$
}

\section{Correction}

The original article shows some incorrect values in Table 1 of the Supplement. The table shown below is as it should be. The volumes at age 4, 6 \& 8 have been changed from " 0.5 to 9.0 " (W-ss) $)^{3}$ x 0.64 in ml, to " 0.5 to 0.9 ".

\section{Author details}

'Department of Pediatric, College of Medicine, The Ohio State University, Nationwide Children's Hospital, Section of Pediatric Endocrinology, 700 Children's Drive, Columbus, OH 43205, USA. ${ }^{2}$ Section of Pediatric Endocrinology, Nationwide Children's Hospital, 700 Children's Drive, Columbus, OH 43205, USA.

Table 1 Similarity of Our Volumes to those Obtained by US (Normalized Smoothed) Reported by Joustra et al. [22]

Received: 28 August 2017 Accepted: 1 September 2017 Published online: 29 September 2017

\section{Reference}

1. Sotos JF, Tokar NJ. Appraisal of testicular volumes: volumes matching ultrasound values referenced to stages of genital development. Int J Pediatr Endocrinol. 2017;2017:7. doi:10.1186/s13633-017-0046-x.

\begin{tabular}{lll}
\hline Age & $\begin{array}{l}(\mathrm{W} \text {-ss })^{3} \times 0.64 \mathrm{in} \mathrm{ml} \text { in } \\
\text { Figure } 2 \text { of manuscript }\end{array}$ & $\begin{array}{l}\text { Range in } \mathrm{ml} \mathrm{[22]} \mathrm{CW} \times \mathrm{W} \times \mathrm{L} \\
\times 0.52) \text { Mean } \pm 2 \mathrm{SD}\end{array}$ \\
\hline 4 & 0.5 to 0.9 & 0.3 to 0.85 \\
6 & 0.5 to 0.9 & 0.3 to 1.1 \\
8 & 0.5 to 0.9 & 0.3 to 1.2 \\
13 & 0.5 to 9.0 & 0.75 to 11.0 \\
14 & 1.5 to 15.5 & 1.5 to 14.5 \\
15 & 1.5 to 15.7 & 3.0 to 16.0 \\
16 & 4.5 to 15.7 & 4.5 to 18.0 \\
17 & 7.7 to 15.7 & 6.3 to 19.0 \\
Adult & 7.7 to 15.7 & 7.5 to 20.0 \\
\hline
\end{tabular}

\footnotetext{
* Correspondence: jsotos@columbus.rr.com

'Department of Pediatric, College of Medicine, The Ohio State University, Nationwide Children's Hospital, Section of Pediatric Endocrinology, 700 Children's Drive, Columbus, OH 43205, USA
} 